\title{
Hotel Imperial: entre restos e encenações
}

\author{
Dúnya Azevedo
}

\author{
Mídia e Narrativa, Programa de Pós-Graduação em \\ Comunicação Social, Pontifícia Universidade Católica de \\ Minas Gerais, Belo Horizonte, Brasil \\ https://orcid.org/0000-0002-1474-6124
}

\section{Hotel Imperial: between traces and scenarios}

Submetido: 23/02/2021 | Revisto: 12/04/2021 | Aceite: 12/04/2021 | Publicado: 10/05/2021

Situado na Rua Guaicurus, no centro de Belo Horizonte, capital do estado de Minas Gerais (Brasil), o edifício que hoje conhecemos como Hotel Imperial foi construído na década de 1920 para funcionar como sanatório - local de tratamento de moléstias contagiosas. Foi na década de 1940 que o governo de Juscelino Kubistchek o transformou em hotel, reconstituindo-o em estilo art déco. Nessa época, os hotéis da região ainda se caracterizavam por abrigar famílias vindas do interior e de outros estados. Mais tarde os apartamentos foram adaptados com o objetivo de servir como local de prostituição e, hoje, pertencente à Santa Casa de Belo Horizonte, o prédio encontra-se fechado há mais de 10 anos e mantém o título de "Hotel". A peça teatral Rua das Camélias, de Belo Horizonte, estreou nesse local em novembro de 2016 reconstituindo o cenário da prostituição.

Ao chegar àquele ambiente pela primeira vez para assistir à peça teatral, me senti lançada a esse universo desconhecido e estranho para mim. O mistério que cercava toda aquela encenação me levou a imaginar esse outro tempo em que prostitutas e clientes por ali transitavam numa atmosfera de sedução e negociação, o burburinho dos corredores, as histórias de cada um que ali passou.

Curiosa, volto na semana seguinte para fotografar. Percorro, então, os ambientes vazios como quem invade a intimidade alheia, e percebo que a energia de tantas almas que passaram por aquele local parece impregnada nas paredes, nos ambientes, nos vestígios. Sinto-me um pouco como aquele trapeiro da História, definido por Walter Benjamin e lembrado por Georges Didi-Huberman (2015), que nos diz que "é na impureza, na escória das coisas que sobrevive o Outrora" (p. 120). Caminho pelos cômodos lentamente e fotografo.

A fotografia pode ser considerada uma ferramenta privilegiada para a reflexão sobre a experiência da memória, pois, ao mesmo tempo em que evoca o passado, ela constrói outras realidades. Nessas imagens, procuro criar um jogo, uma tensão entre passado e presente, entre ficção e realidade. Refiro-me aqui a uma dupla ficção: uma dada pela própria peça teatral, cujos vestígios estão nos objetos deixados pelos atores, outra dada por meu próprio imaginário, aquele que me permite fabular. Em algumas imagens, as aparições fantasmagóricas voltam à superfície para mostrar que o agora está impregnado de passado. Não seria a imaginação a responsável por introduzir o afeto no trabalho documental e por permitir que o fotógrafo crie "ficção" no documento?

Percebo que há nesse local outras camadas de tempo que minha imaginação poderia acessar, pois o edifício já abrigou famílias que viajavam a passeio e enfermos que vinham para a capital em busca de cura. Lugar onde todos os tempos se entrelaçam, se confundem e se bifurcam, antigo palco de diversas histórias e muitos afetos, o Hotel Imperial está hoje sob a guarda de uma "Santa Casa" e localiza-se na Rua Guaicurus, palavra de origem indígena. O termo guaicurú, segundo Guido Boggiani, se divide etimologicamente em Guai, que significa "habitante, nativo, combativo, malvado, traidor"; e curu, que significa "sarna, pele suja" (Herberts, 1998, p. 41). Guaicuru tem então o significado pejorativo de "gente malvada e suja". Coincidência ou não, as prostitutas são vistas socialmente como restos, sujeira, escória, trapos da história. 


\section{Vista}

41917 N.o 7 (2021): Janeiro - junho 2021 | https://doi.org/10.21814/vista.3327

Nesse local de tempos superpostos, escolho imaginar, assim como os atores da peça Rua das Camélias, o cenário da prostituição, cujos vestígios são evidentes. Adentro cada cômodo com a curiosidade de um voyeur e, nesse ato, convido os espectadores a uma incursão pelos restos desse antigo prostíbulo onde descubro um misto de precariedade, melancolia, dor e prazeres.

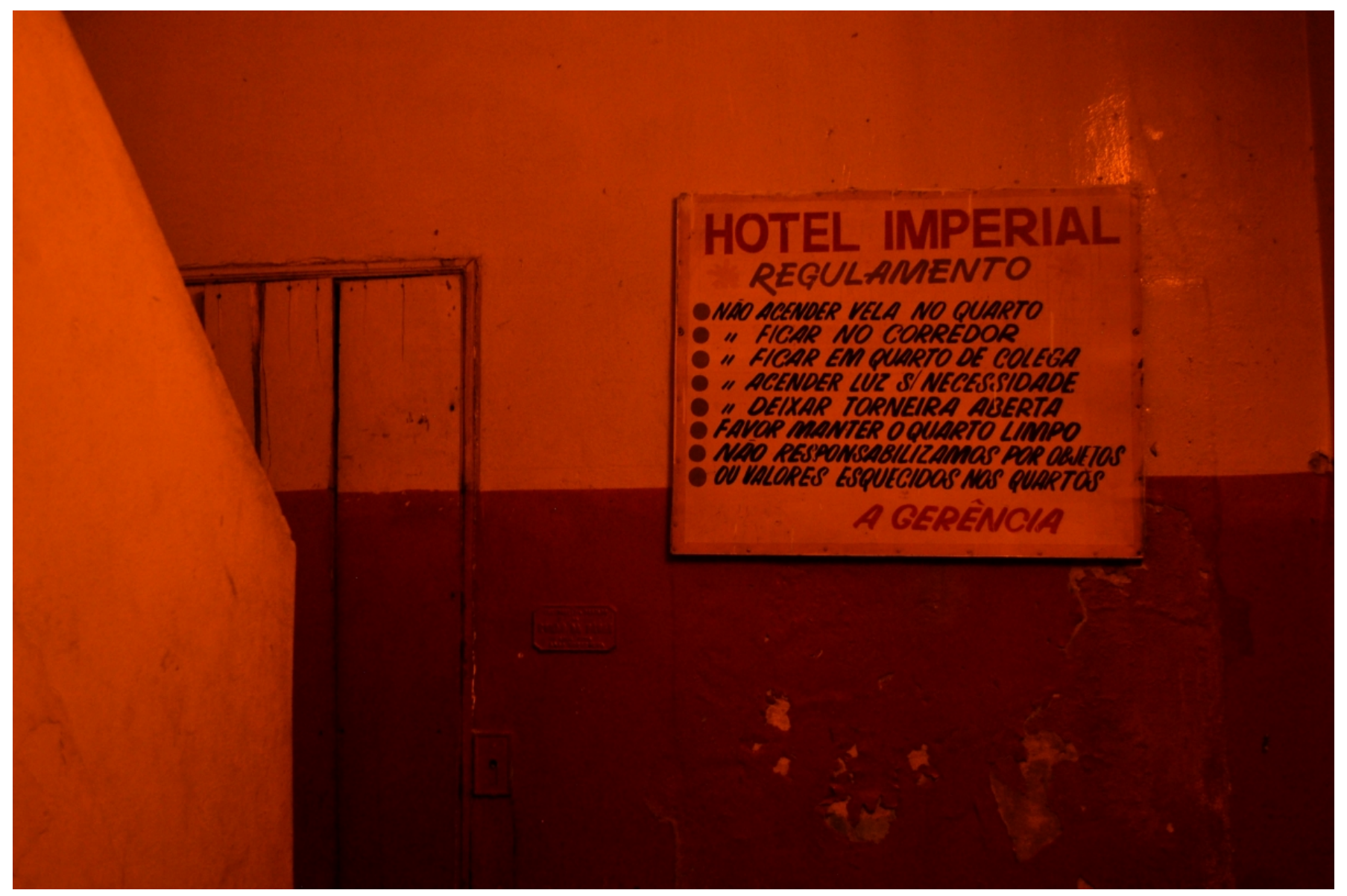

Figura 1. Entrada 


\section{Vista}

4917 N.o 7 (2021): Janeiro - junho 2021 | https://doi.org/10.21814/vista.3327

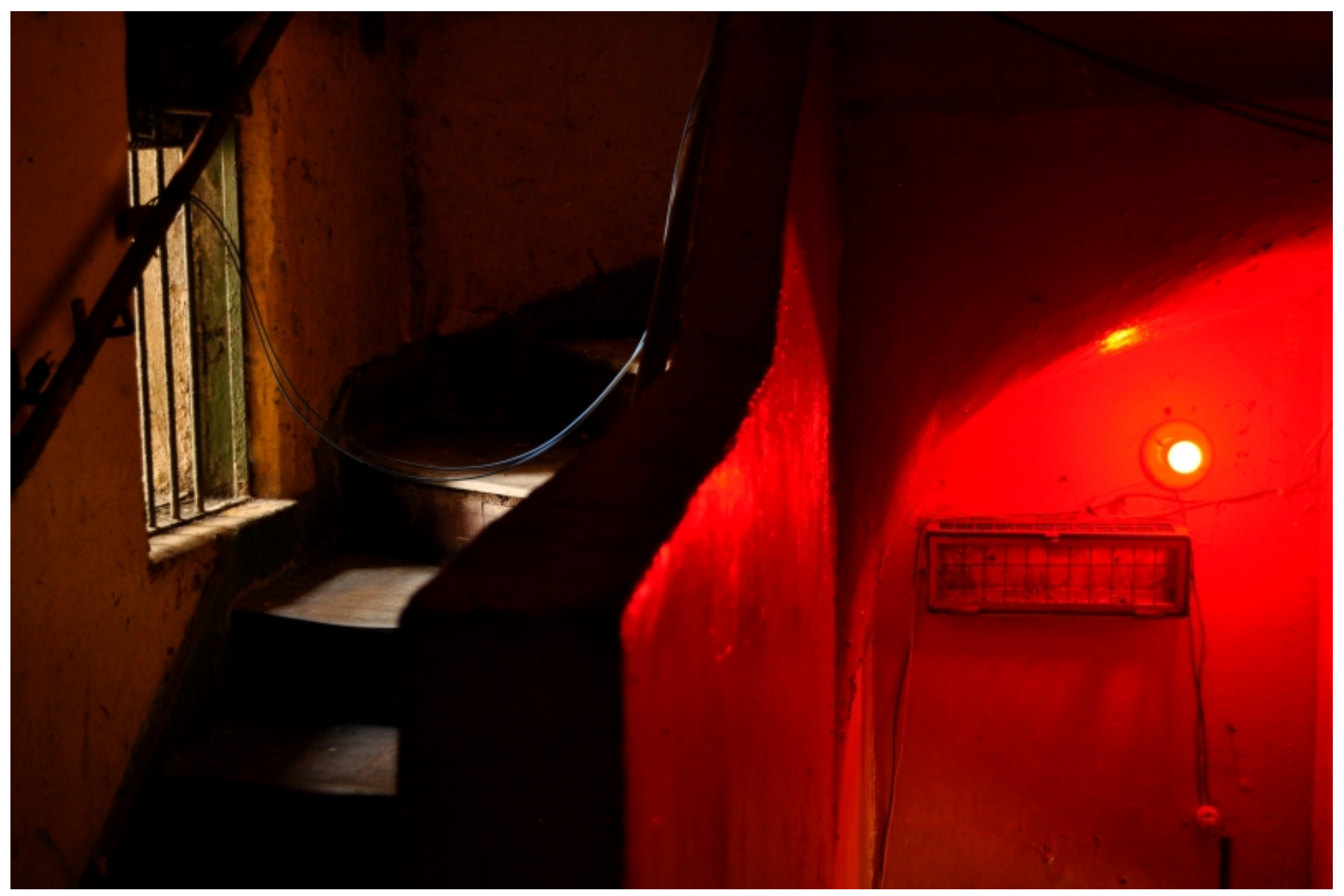

Figura 2. Precariedade 


\section{Vista}

4917 N.o 7 (2021): Janeiro - junho 2021 | https://doi.org/10.21814/vista.3327

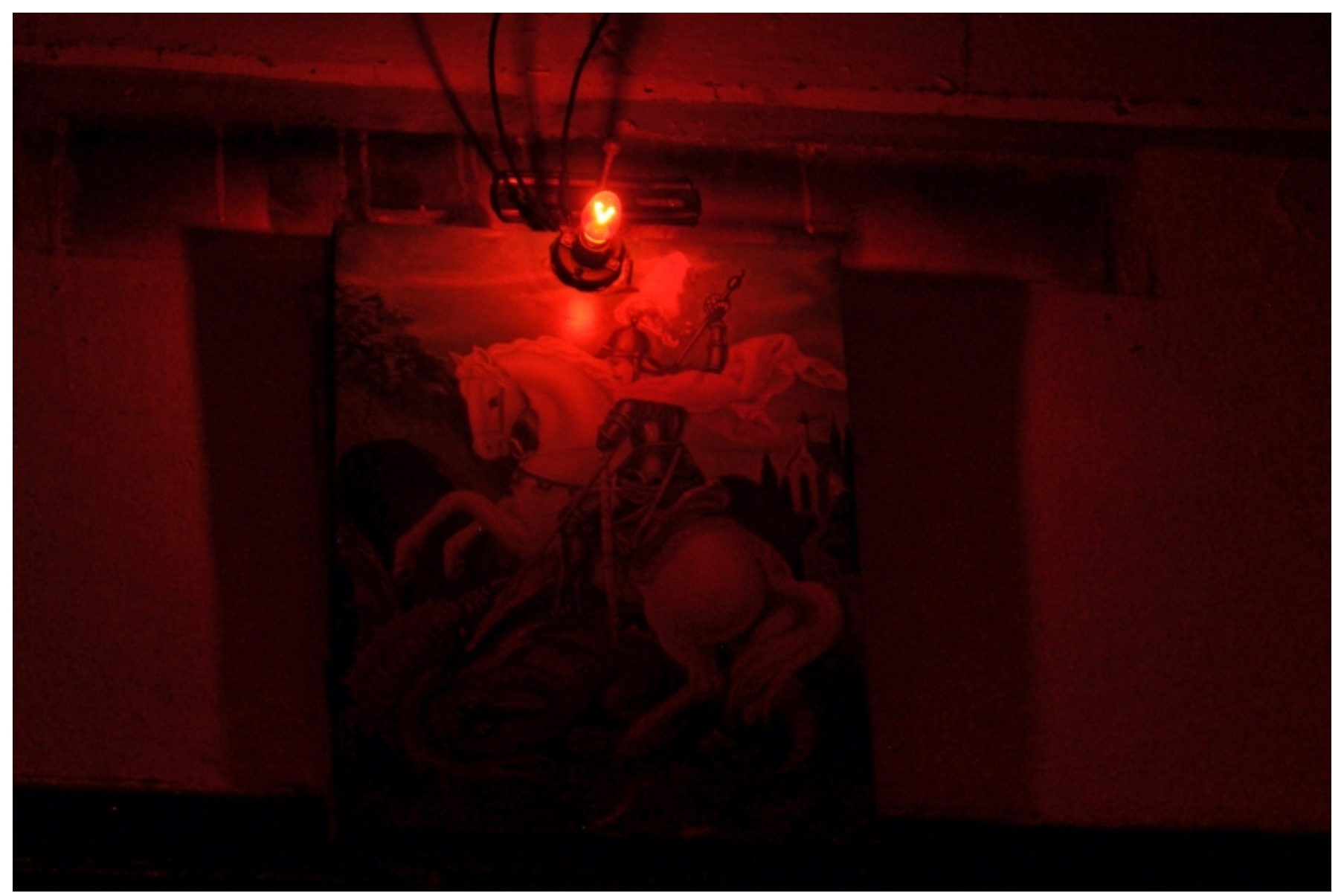

Figura 3. Protetor dos guerreiros 


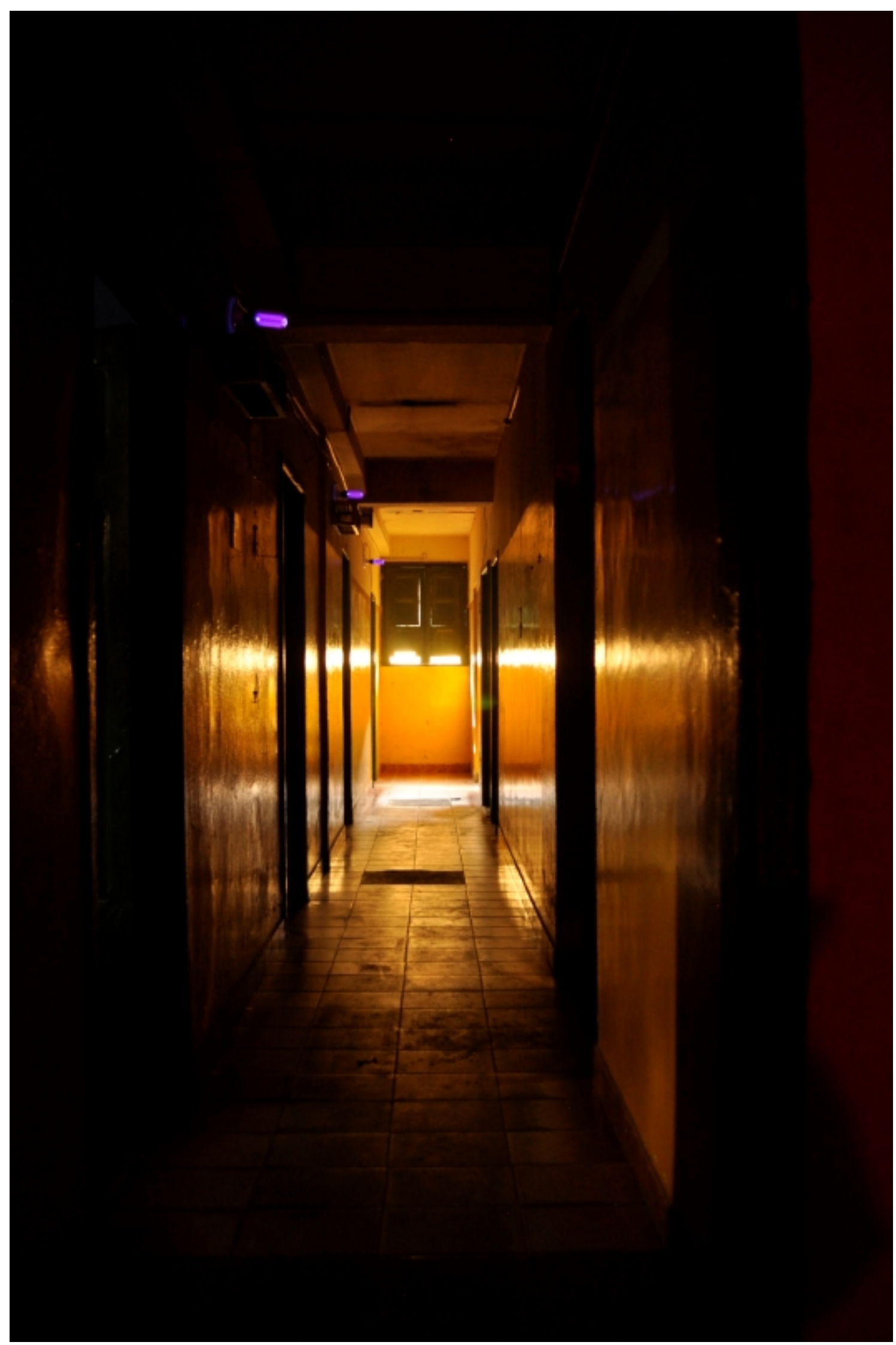

Figura 4. Passagem 1 


\section{Vista}

4181 ‥ 7 (2021): Janeiro - junho 2021 | https://doi.org/10.21814/vista.3327

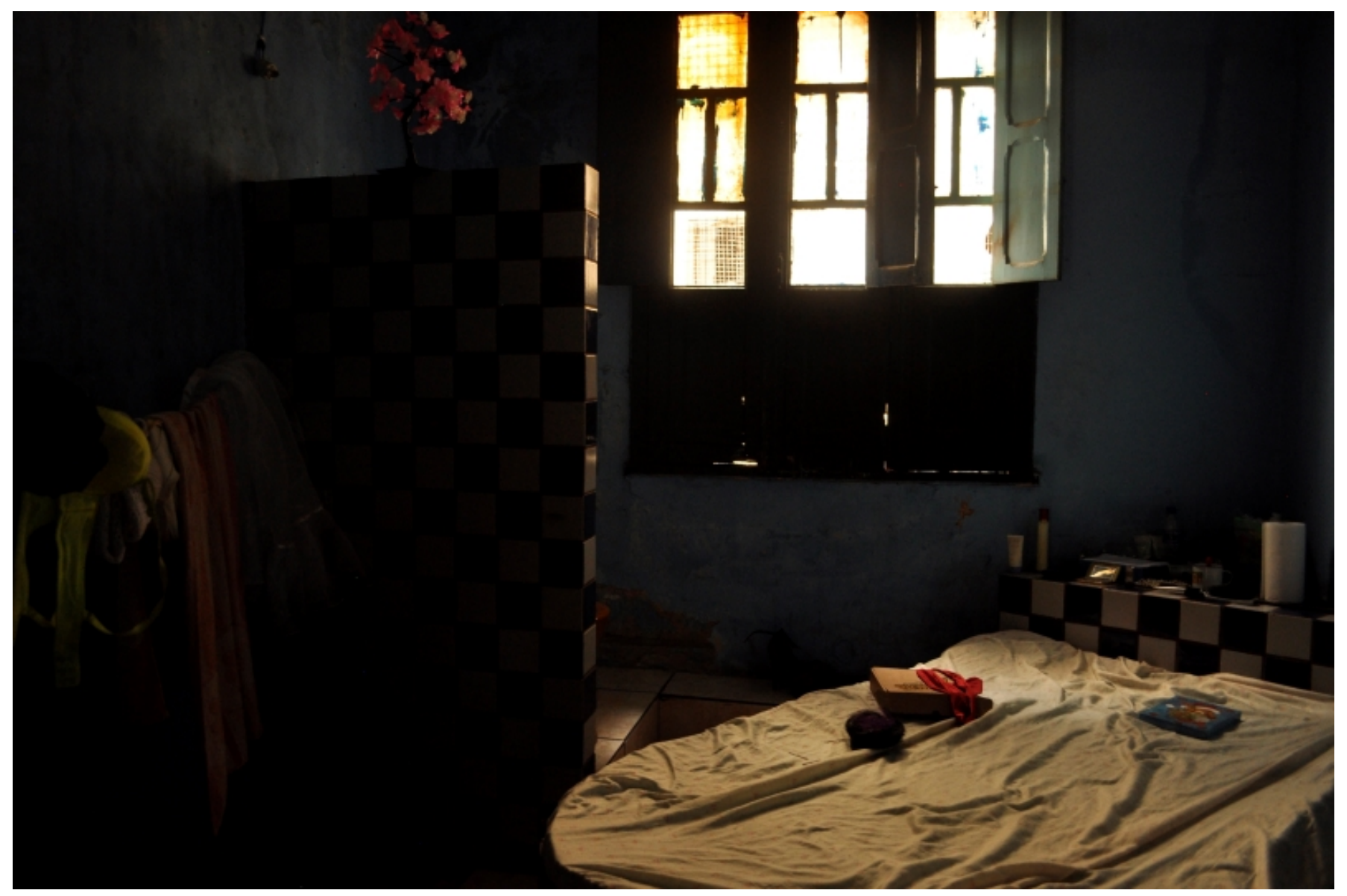

Figura 5. Quarto 1 


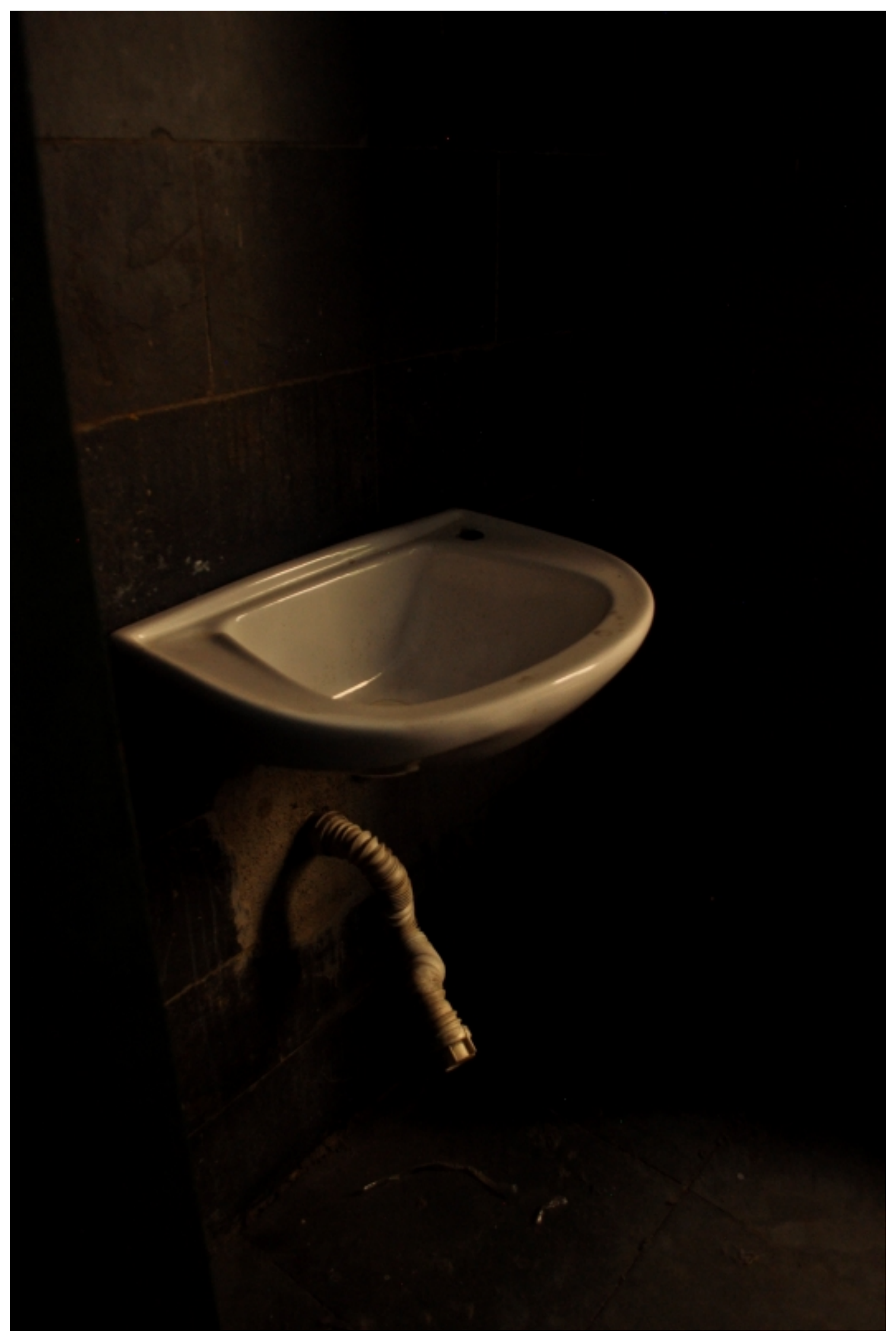

Figura 6. Restos 1 


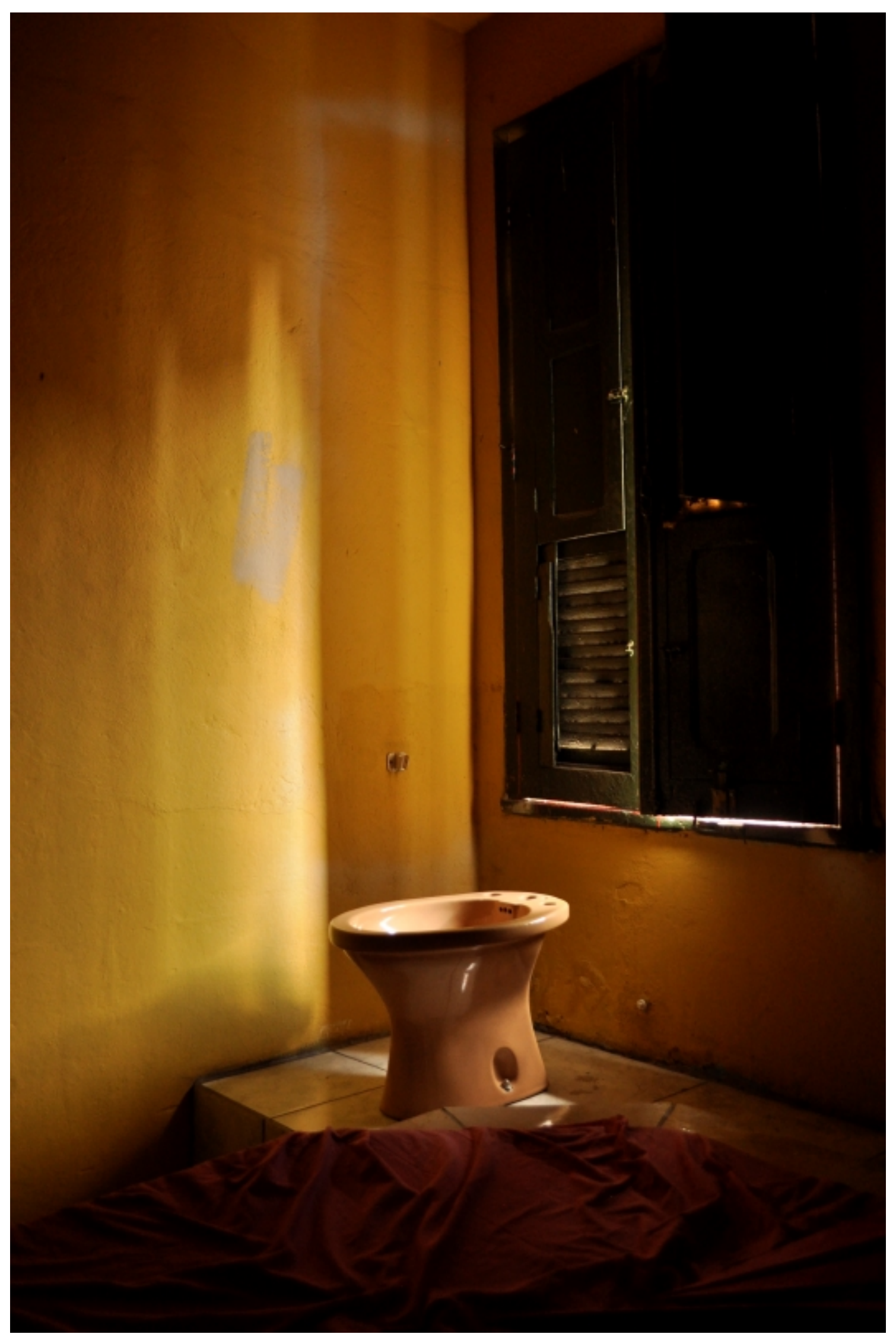

Figura 7. Restos 2 


\section{Vista}

4917 N.o 7 (2021): Janeiro - junho 2021 | https://doi.org/10.21814/vista.3327

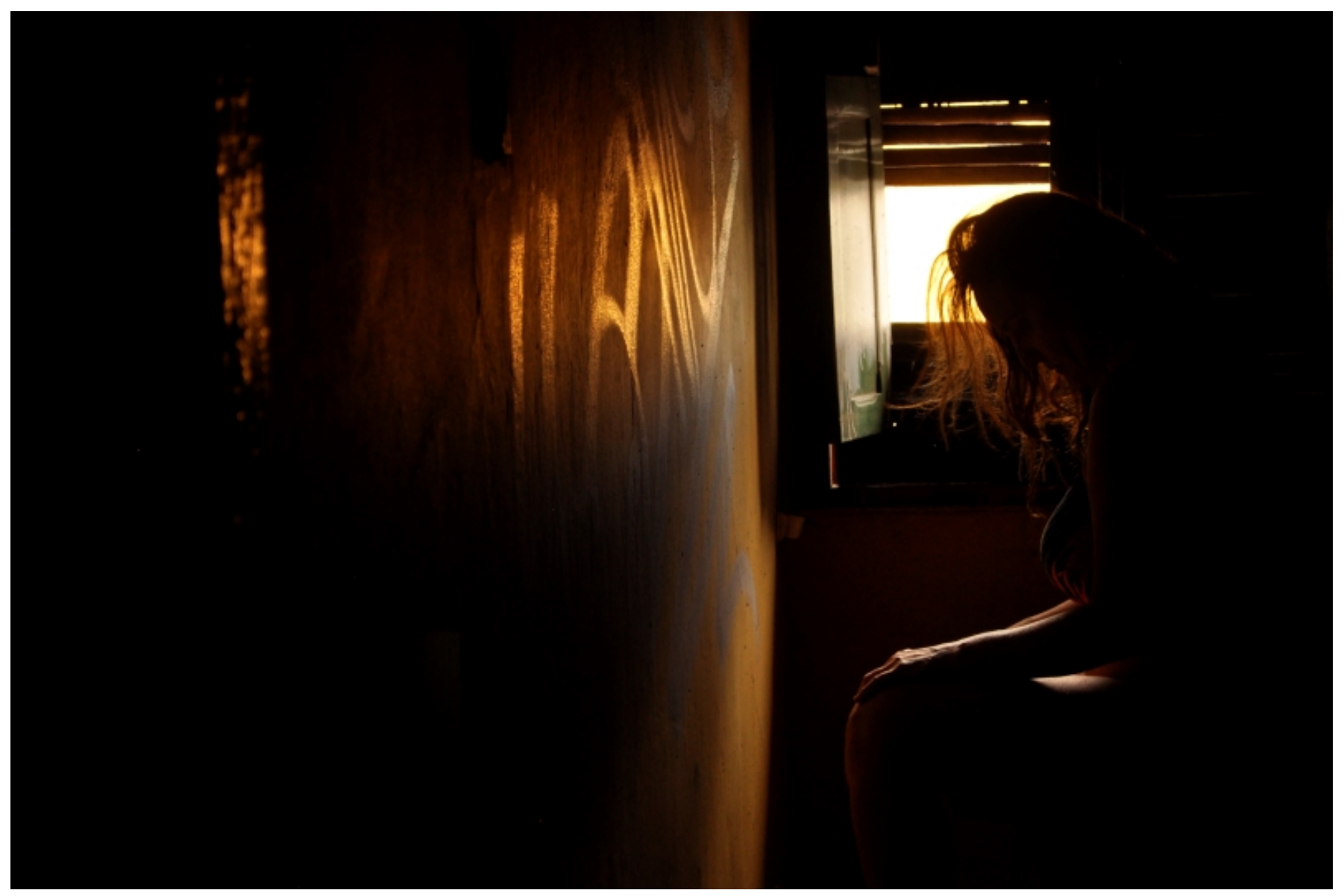

Figura 8. Rua das Camélias 


\section{Vista}

41917 N.. 7 (2021): Janeiro - junho 2021 | https://doi.org/10.21814/vista.3327

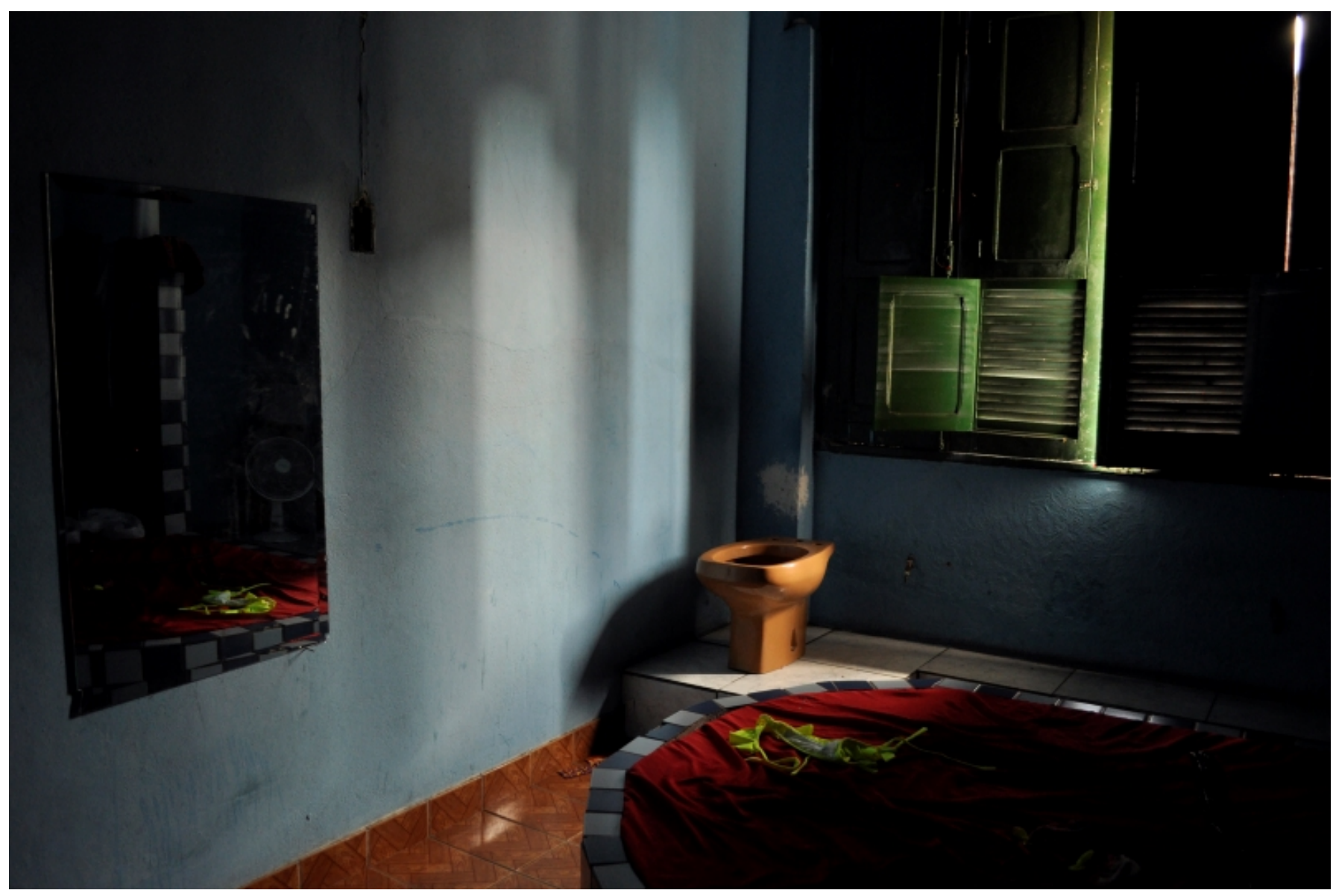

Figura 9. Restos 3 


\section{Vista}

4181 N. 7 (2021): Janeiro - junho 2021 | https://doi.org/10.21814/vista.3327

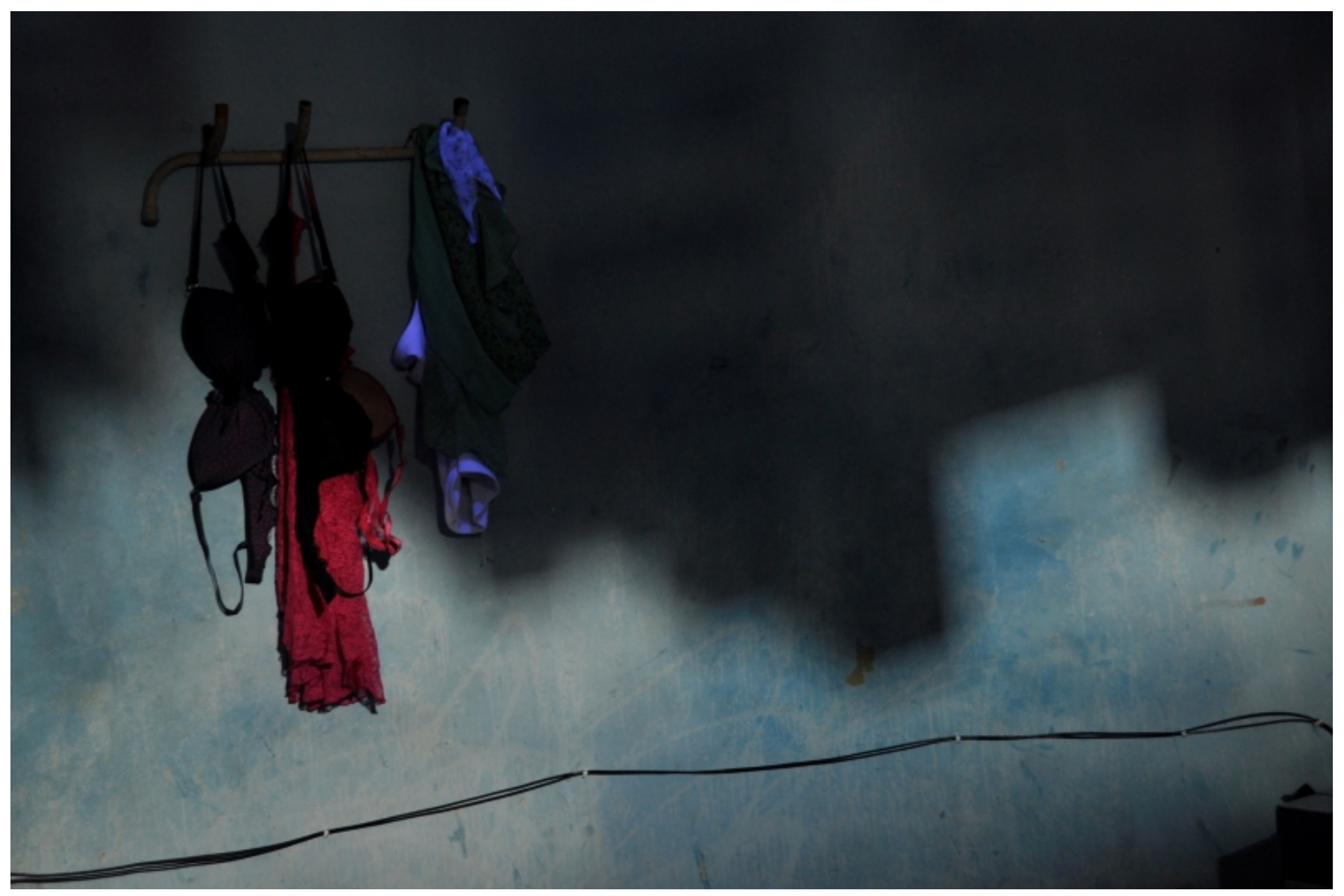

Figura 10. Rua das Camélias 


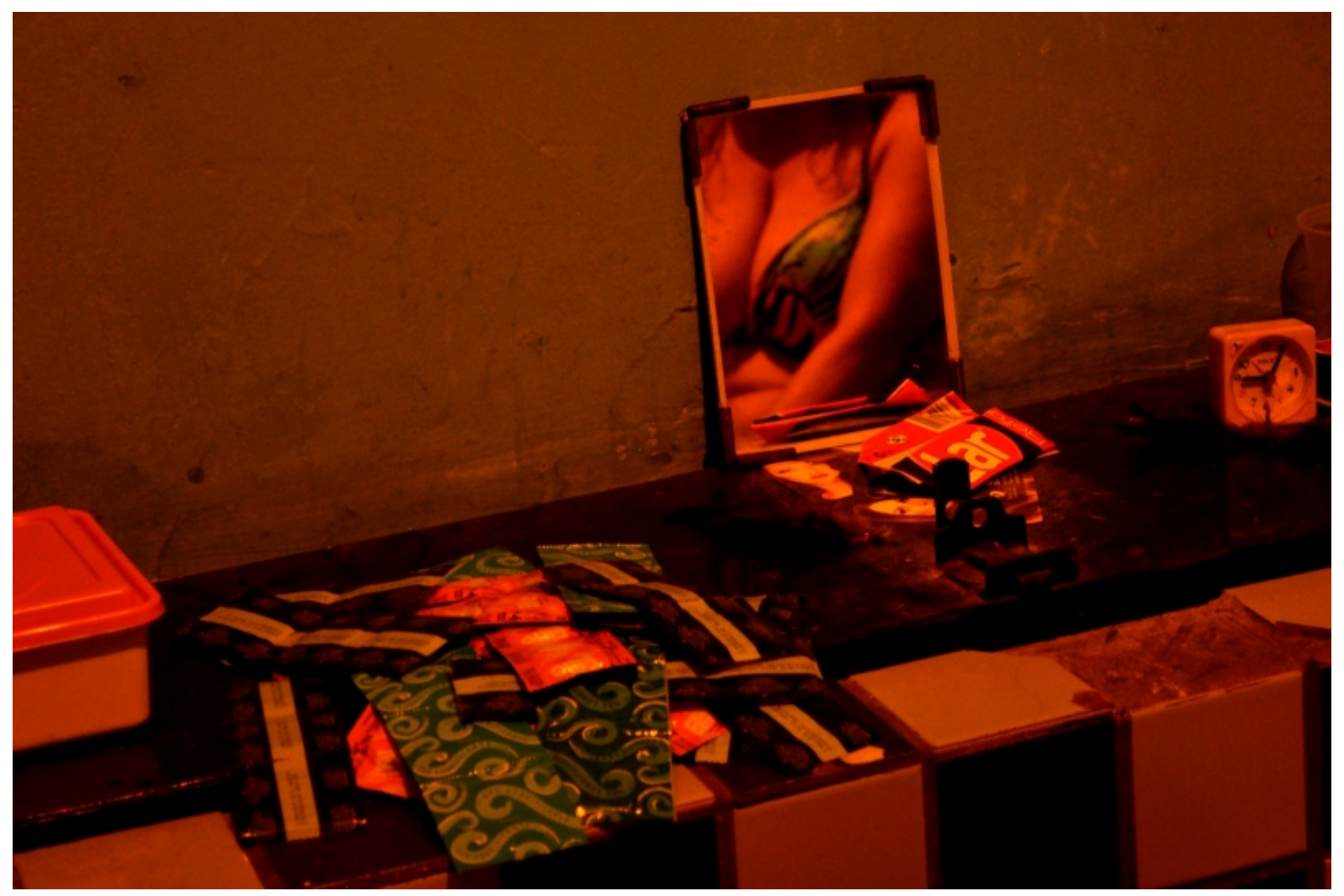

Figura 11. Rua das Camélias 


\section{Vista}

4917 N.o 7 (2021): Janeiro - junho 2021 | https://doi.org/10.21814/vista.3327

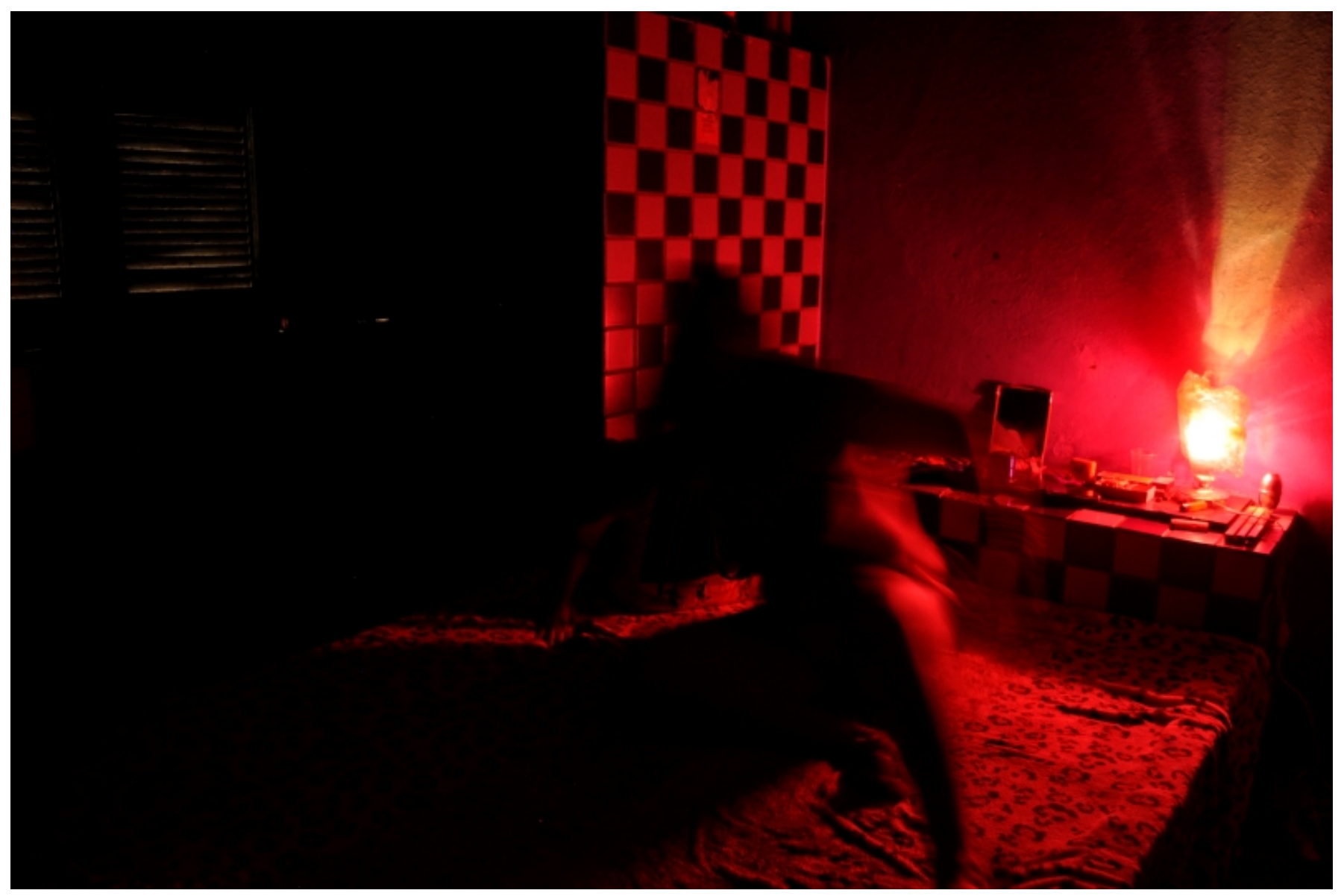

Figura 12. Rua das Camélias 


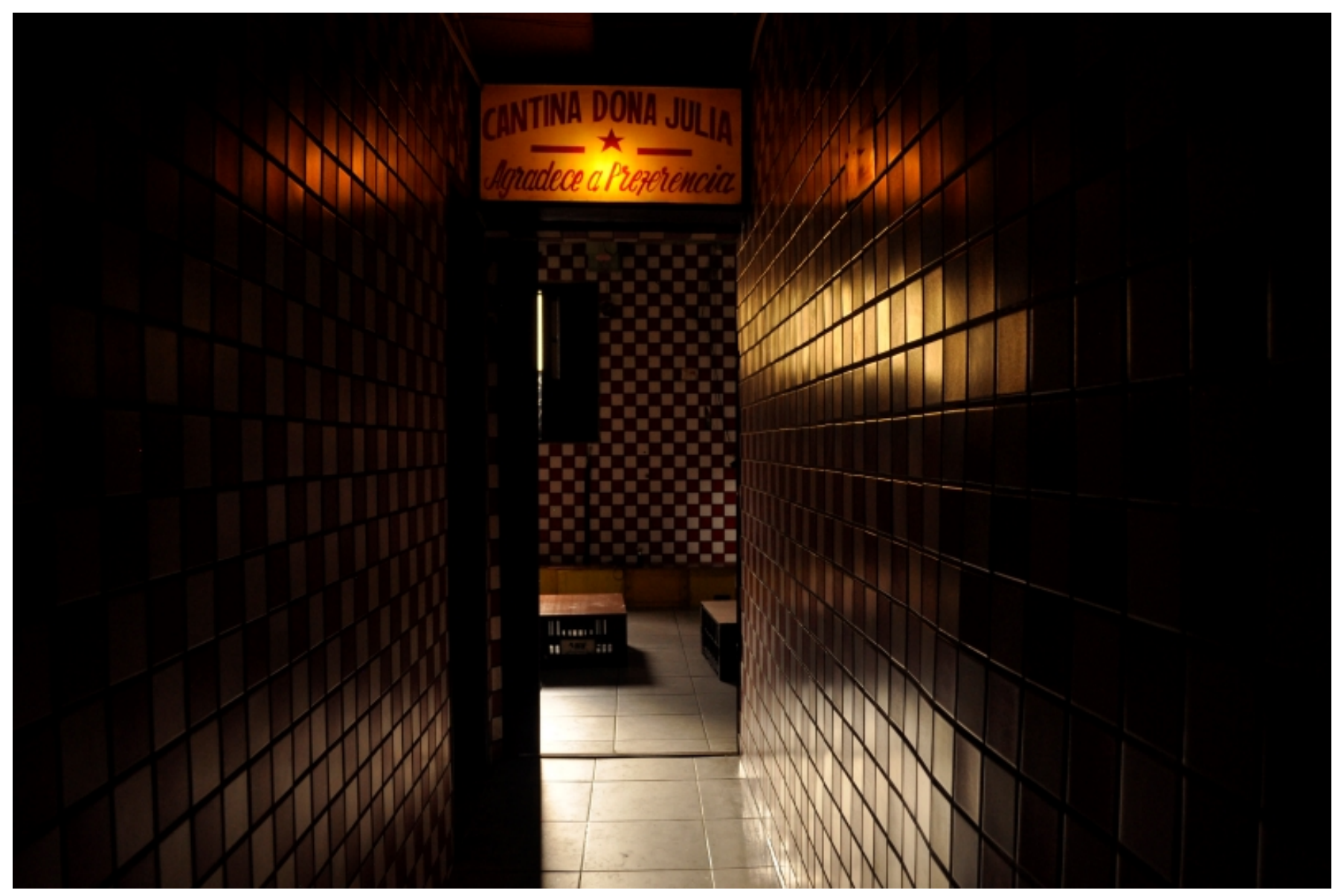

Figura 13. Passagem 2 


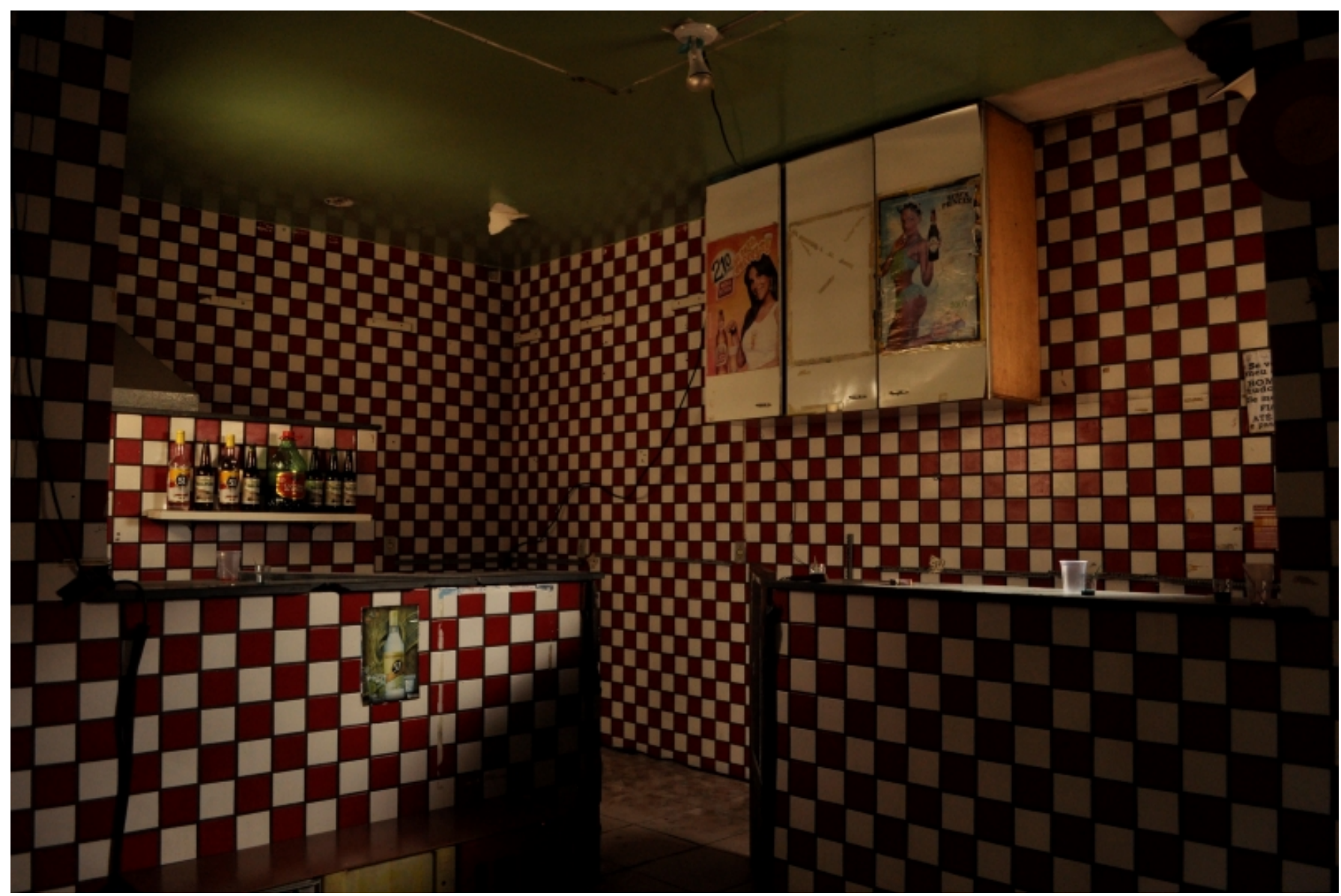

Figura 14. Cantina

\section{Agradecimentos}

Agradeço a Regina Ganz, atriz da peça Rua das Camélias que possibilitou meu acesso ao Hotel Imperial.

\section{Nota biográfica}

Dúnya Azevedo é doutora na área de Comunicação Social pela Universidade Federal de Minas Gerais, com período sanduíche na Université Paris 1 Pantheon-Sorbonne (Paris, França); é mestre em Design pela Escola Superior de Desenho Industrial, Universidade do Estado do Rio de Janeiro; possui graduação em Comunicação Social (Pontifícia Universidade Católica, Minas Gerais). Tem experiência profissional na área de Comunicação Social com ênfase em Design e Fotografia. A sua pesquisa está voltada para os sentidos da imagem fotográfica e as relações entre arte, documento e memória. Ministra cursos de curta duração e workshops ligados a fotografia, design, arte e cultura. Tem experiência de 20 anos como professora em cursos de graduação, especialização e mestrado, ministrando disciplinas ligadas à imagem, fotografia, semiótica, teoria da imagem, linguagem visual. É professora vinculada ao grupo de pesquisa "Mídia e Narrativa", do Programa de PósGraduação em Comunicação Social da Pontifícia Universidade Católica de Minas Gerais, Belo Horizonte, Brasil.

ORCID: https://orcid.org/0000-0002-1474-6124

Email: dunya.azevedo@gmail.com 
Morada: Av. Trinta e Um de Março, 1020, Prédio 93 - Dom Cabral - Belo Horizonte/MG - CEP: 30535-000, Brasil

\section{Referências}

Didi-Huberman, G. (2015). Diante do tempo: História da arte e anacronismo das imagens. Editora UFMG.

Herberts, A. L. (1998). História dos Mbayá-Guaicuru, panorama geral. Fronteiras Revista História UFMS, 2(4), 39-76.

Este trabalho está licenciado com uma Licença Creative Commons - Atribuição 4.0 Internacional. 